Carlos de Salles Soares Neto

\title{
Autoria de Documentos Hipermídia Orientada a Templates
}

\section{TESE DE DOUTORADO}

DEPARTAMENTO DE INFORMÁTICA

Programa de Pós-graduação em Informática 
Carlos de Salles Soares Neto

\section{Autoria de Documentos Hipermídia Orientada a Templates}

Tese apresentada como requisito parcial para obtenção do título de Doutor pelo Programa de PósGraduação em Informática da PUC-Rio.

Orientador: Luiz Fernando Gomes Soares Co-Orientador: Clarisse Sieckenius de Souza 
Carlos de Salles Soares Neto

\section{Autoria de Documentos Hipermídia Orientada a Templates}

Tese apresentada como requisito parcial para obtenção do título de Doutor pelo Programa de Pós-Graduação em Informática do Departamento de Informática do Centro Técnico Científico da PUC-Rio. Aprovada pela Comissão Examinadora abaixo assinada.

Prof. Luiz Fernando Gomes Soares Orientador

Departamento de Informática - PUC-Rio

Profa. Clarisse Sieckenius de Souza

Co-Orientador

Departamento de Informática - PUC-Rio

Prof. Renato Fontoura de Gusmão Cerqueira

Departamento de Informática - PUC-Rio

Profa. Simone Diniz Junqueira Barbosa

Departamento de Informática - PUC-Rio

Profa. Maria da Graça Campos Pimentel

Universidade de São Paulo - USP

Prof. Jair Cavalcanti Leite Universidade Federal do Rio Grande do Norte - UFRN

Prof. José Eugenio Leal

Coordenador Setorial do Centro Técnico Científico - PUC-Rio

Rio de Janeiro, 2 de setembro de 2010 
Todos os direitos reservados. É proibida a reprodução total ou parcial do trabalho sem autorização da universidade, do autor e dos orientadores.

\section{Carlos de Salles Soares Neto}

Graduado em Ciências da Computação pela Universidade Federal do Maranhão (UFMA) em 2000. Mestre em Ciências em Informática na área de Redes de Computadores e Sistemas Distribuídos pela Pontifícia Universidade Católica do Rio de Janeiro (PUC-Rio) em 2003, onde concentrou os estudos na especificação arquitetural de Serviços com QoS. Desde 2002 atua como pesquisador associado do Laboratório TeleMídia da PUC-Rio, onde trabalhou em diversos projetos em redes de computadores, aplicações hipermídia e autoria de aplicações interativas para TV digital. Foi professor de cursos de pós-graduação em Redes de Computadores no CCE/PUC-Rio e UFMA. Atualmente é professor assistente do Departamento de Informática da UFMA, onde atua como um dos coordenadores do Laboratory of Advanced Web Systems (LAWS).

Ficha Catalográfica

Soares Neto, Carlos

Autoria de Documentos Hipermídia Orientada a Templates / Carlos de Salles Soares Neto; orientador: Luiz Fernando Gomes Soares; co-orientador: Clarisse Sieckenius de Souza. - 2010.

146 f. : il. ; $30 \mathrm{~cm}$

Tese (Doutorado em Informática)-Pontifícia Universidade Católica do Rio de Janeiro, Rio de Janeiro, 2010.

Incluí referências bibliográficas.

Autoria Hipermídia; Linguagens declarativas hipermídia; Nested Context Language; Templates; ADLs; Composições Hipermídia; Modelos Conceituais Declarativos. 
Este trabalho é dedicado

A Deus, por ser.

A Lylian e Mateus, pela família que formamos.

Aos meus pais Carlos e Raimunda, meus irmãos Hérlon e Dinamene, e meus sobrinhos João Carlos (in memoriam), Hérlon Junior, Vinícius, Luiz Ricardo e Arthur. 


\section{Agradecimentos}

Obrigado a Deus.

Ao meu amigo e orientador Luiz Fernando Gomes Soares, pelas diversas aulas magistrais em todos esses anos. Espero que minha atenção e dedicação tenham valido para aprender suas lições e que possa devolver ao mundo pelo menos a metade do que recebi de você.

À minha co-orientadora Clarisse Sieckenius de Souza, pelo apoio incondicional e crença em meu trabalho. No meu pior momento durante essa jornada, foi ouvindo suas palavras hábeis que continuei nos trilhos.

Aos meus pais. Vocês deram a mim a educação, cultura e religião necessárias para persistir e chegar onde bem desejar. Meus sucessos são seus. Meus fracassos cabem apenas a mim.

À Lylian e Mateus, pela paciência de terem vivido essa tese com minha ausência. Sou seus agora! Aos meus irmãos Dina e Hérlon e meus sobrinhos. Amo muito vocês.

À família TeleMídia, pelos anos de convívio e extrema dedicação profissional. Fazer parte desse time é uma honra e orgulho. Não vou me arriscar a falar o nome de todos para não ser injusto e cruel com alguns, mas queria agradecer especialmente ao Moreno, Álvaro, Romualdo, Márcio, Rogério, Roberto, Eduardo, José Geraldo, Bruno, Bidu, Ricardo, Guilherme, Rafael, Laiola. 
Ao Jansen e Malveira, meus eternos mestres de matemática. Certamente foi em seus exemplos que me inspirei para ser professor.

Aos amigos de infância Fabinho, Motta Jr., Farofa, César, Neto B., Danica, Rondi. Vocês são até hoje algumas das mais fortes influências em minha vida.

Agradeço à CAPES, PUC-Rio, UFMA e Laboratório TeleMídia pela infraestrutura e todo apoio que foram fundamentais para a realização deste trabalho.

Quando criança, criei uma oração que faço todos os dias. Não costumo contá-la para ninguém mas acho que esse é o melhor local para torná-la pública. Eis: "A Deus nas alturas, obrigado por esse dia e daí-me forças para mais dias e dias de felicidade iguais a este que estou tendo hoje. Obrigado." 


\section{Resumo}

Soares Neto, Carlos; Soares, Luiz Fernando Gomes (Orientador); de Sousa, Clarisse Sieckenius (Co-Orientador) Autoria de Documentos Hipermídia Orientada a Templates. Rio de Janeiro, 2010. 146p. Tese de Doutorado Departamento de Informática, Pontifícia Universidade Católica do Rio de Janeiro.

Nos últimos anos, tem crescido a demanda por aplicações hipermídia, as quais relacionam objetos de áudio, vídeo, texto, imagem, etc. no tempo e no espaço. Uma aplicação hipermídia é especificada formalmente em um documento. É comum agrupar um conjunto de aplicações estruturalmente ou semanticamente similares entre si como uma família de documentos. Modelos conceituais para autoria hipermídia são usados como base para a especificação de documentos, mas eles não são satisfatórios para definir famílias de documentos. Este trabalho apresenta como contribuição um método para a autoria hipermídia baseado na identificação dessas famílias e sua instanciação visando à criação de novos documentos. Esse método endereça a autoria de documentos hipermídia como uma prática social, onde autores mais especializados colaboram para ajudar e facilitar a tarefa de autores menos especializados. Outra contribuição deste trabalho é a definição de uma linguagem para a especificação de famílias de documentos, chamada TAL (Template Authoring Language), a qual pode ser empregada no método proposto. TAL se apóia principalmente na extensão do conceito de composição, habitualmente presente em modelos hipermídia. Em TAL, composições podem ser incompletas, com alguns de seus elementos internos propositalmente deixados em aberto e com regras restringindo a forma como esses elementos ausentes podem ser inseridos na composição. Para se chegar a essa linguagem, um estudo empírico foi realizado investigando a aprendizagem e o emprego de Nested Context Language (NCL). A escolha de NCL se deu por ela se basear em um modelo com composicionalidade que pode 
ser estendido para atender a famílias de documentos, e por ela ser empregada na autoria de documentos hipermídia e passível de ser usada por perfis profissionais diversos e não apenas programadores. Assim, uma terceira contribuição naturalmente decorrente deste trabalho é oferecer diretrizes para a evolução de NCL, em especial aperfeiçoando sua usabilidade.

\section{Palavras-chave}

Autoria Hipermídia; Linguagens declarativas hipermídia; Nested Context Language; Templates; ADLs; Composições Hipermídia; Modelos Conceituais. 


\section{Abstract}

Soares Neto, Carlos; Soares, Luiz Fernando Gomes (Advisor); de Sousa, Clarisse Sieckenius (Co-Advisor). Template Based Authoring of Hypermedia Documents. Rio de Janeiro, 2010. 146p. DSc. Thesis Departamento de Informática, Pontifícia Universidade Católica do Rio de Janeiro.

In the past years, it has increased the demand for hypermedia applications, which relate objects of audio, video, text, images, etc. in time and space. A hypermedia application is formally specified in a document. It is usual to group a set of applications structurally and semantically similar to each other as a documents family. Conceptual models for hypermedia authoring are the basis for documents specification, but they are not satisfactory to define documents families. This work presents as contribution a method for hypermedia authoring based in the identification of these families and their instantiation in order to create new documents. This method addresses the hypermedia document authoring as a social practice, where specialist authors collaborate to help and to ease the task of less skilled authors. Another contribution of this work is to define a language for the specification of these documents families, named TAL (Template Authoring Language), which can be applied in the proposed method. TAL relies mainly on extending the concept of composition, usually present in hypermedia models. In TAL, compositions can be incomplete, with a few of its internal elements purposely left undefined and with restriction rules on how these missing elements may be included in the composition. In order to achieve this language, an empirical study was conducted investigating the learning and use of Nested Context Language (NCL). The choice of NCL relies on the fact that it is based in a compositional model that can be extended to specify documents families, and because it is used by various professional profiles and not just programmers in the hypermedia document authoring. Thus, a third contribution 
due to this work is to provide guidelines to NCL evolution, especially improving its usability.

\section{Keywords}

Hypermedia Authoring; Declarative Hypermedia Languages; Nested Context Language; Templates; ADLs; Hypermedia Compositions; Conceptual Models. 


\section{Sumário}

1 Introdução 16

1.1. Objetivos, Método e Principais Contribuições 21

1.2. Organização da tese 22

2 Autoria em Nested Context Language 24

2.1. Introdução à NCL 24

2.2. Estudo empírico com NCL 26

2.2.1. Especificação de Conteúdos Digitais com NCL: Perfil de Usuários e Tarefas $\quad 28$

2.2.2. Metodologia do Estudo Empírico 30

2.2.3. Caracterização do perfil das turmas de alunos 30

2.2.4. Análise e Interpretação de Dados 32

2.3. Estudo Analítico sobre Reúso e Importação em NCL 44

2.3.1. Reúso em Aplicações Interativas para TV Digital 46

2.3.2. Reúso em uma mesma aplicação NCL 48

2.3.3. Reúso entre aplicações NCL 58

2.3.4. Analisando a Usabilidade da NCL 63

2.4. Requisitos para uma Linguagem de Autoria de Famílias de Documentos levantados pelos Estudos de NCL 79

3 Templates de Documentos 86

3.1. Templates baseados em ADLs 86

3.2. Templates baseados em XTemplate 89

3.3. Templates em SMIL Timesheets 92

3.4. Requisitos para uma Linguagem de Especificação de Famílias de Documentos Vindos de outras Linguagens 95 
3.5. Resumo dos requisitos de uma linguagem para autoria de famílias de documentos

4 TAL: Template Authoring Language 98

4.1. Exemplo de Uso: Template Botão-Texto-Imagem 98

4.2. Conceitos Gerais de TAL 101

4.3. Definição de TAL 104

4.4. Seletores da Linguagem 109

4.5. Linguagem de Restrições 110

4.6. Linguagem de Relacionamentos 112

4.7. Exemplos de Templates 114

4.7.1. Slideshow de fotos 114

4.7.2. Template Botão-Texto-Slideshow 118

4.7.3. Template Padrão de Interface 119

5 Método de Autoria Orientado a Templates $\quad 121$

5.1. Método de Autoria Orientado a Templates 121

5.2. Aplicações interativas para TV digital: cenário de uso do método de autoria orientado a templates $\quad 125$

5.3. NCLWizard: caso de uso do método de autoria orientado a templates baseado em ferramentas wizard 126

$\begin{array}{ll}6 \text { Conclusões } & 131\end{array}$

6.1. Revisitando os requisitos para uma linguagem de autoria de famílias de documentos 132

6.2. Contribuições da Tese 135

6.3. Trabalhos Futuros 136

$\begin{array}{ll}7 \text { Referências } & 138\end{array}$

Apêndice A - XML Schema de TAL 144 


\section{Lista de Figuras}

Figura 1. Aplicativo de TV com sincronismo de mídias e interatividade do usuário.

Figura 2. Reúso de Conteúdo.

Figura 3. Bases de regiões para múltiplos dispositivos. 50

Figura 4. Base de descritores. 52

Figura 5. Alternativas para a definição do elemento <media>. 52

Figura 6. Reúso de objeto de mídia. 53

Figura 7. Bases de transições e regras.

Figura 8. Importando e aninhando um documento NCL. 59

Figura 9. Importando um documento NCL para ser exibido em uma região definida no documento importador. 60

Figura 10. Importando Bases e Documentos. 62

Figura 11. Organizando a aplicação das dimensões CDN no contexto do reúso NCL. $\quad 67$

Figura 12. Composição hipermídia em aberto: um slideshow de fotos. 88 Figura 13. Visões Estrutural e Temporal de um Template de Composição (Santos \& Muchaluat-Saade, 2009). 90

Figura 14. Relacionamentos em XTemplate. 91

Figura 15. Slide-show de fotos em SMIL Timesheets (W3C, 2008c). 94

Figura 16. Exemplos de aplicações que seguem o template Botão-Texto-Imagem: (a) Aplicação sobre saúde da PRODERJ;

(b) Aplicação de Serviços da CAIXA®, desenvolvida pela $\mathrm{HxD}$ Interactive Television.

Figura 17. Visão Estrutural de um Documento seguindo o Template "Botão-Texto-Imagem". 100

Figura 18. Template "Botão-Texto-Imagem". 103

Figura 19. Documento NCL de preenchimento do template "Botão-Texto-Imagem". 104

Figura 20. Especificação do template "Botão-Texto-Imagem". 108

Figura 21. EBNF da linguagem de restrições embutida em TAL. 111

Figura 22. Linguagem para relacionamentos hipermídia. 113 
Figura 23. Documento temporalSlideshow.xml: exibição básica de fotos.

Figura 24. Documento audioSlideshow.xml: slideshow de fotos com música de fundo.

Figura 25. Documento navigationSlideshow.xml: inclunido a navegação por teclas em um slideshow de fotos.

Figura 26. Documento buttontextslideshow.xml: template "Botão-Texto-Slideshow".

Figura 27. Template que restringe menus a quatro eventos de seleção.

Figura 28. Autoria de Documentos Hipermídia Orientada a Templates.

Figura 29. Atores e Arquitetura da ferramenta NCLWizard.

Figura 30. Exemplo de especificação XWizard e a respectiva interface gerada. 


\section{Lista de Tabelas}

Tabela 1. Dados coletados sobre NCM nos Cursos 2 e 3 . 38

Tabela 2. Elementos e atributos da linguagem TAL. 105

Tabela 3. Seletores da Linguagem TAL. 110

Tabela 4. Estrutura da linguagem XWizard. 129 